\title{
FAKTOR-FAKTOR YANG MEMPENGARUHI PETANI DALAM ALIH KOMODITI KOPI (Coffee sp) KE KAKAO (Theobrroma cacao L. ) DI DESA TERTAP KECAMATAN JARAI KABUPATEN LAHAT SUMATERA SELATAN
}

\author{
INFLUENCED FACTORS TO FARMERS IN CONVERTING COFFEE \\ (Coffee sp) TO CACAO (Theobrroma cacao L.) IN TERTAP VILLAGE, \\ SUBDISTRICT JARAI DISTRICT OF LAHAT, SOUTH SUMATERA
}

\author{
M. Agus Maryanto, Musriyadi Nabiu, dan Septri Widiono \\ Jurusan Sosial Ekonomi Pertanian, Fakultas Pertanian Universitas Bengkulu
}

\begin{abstract}
This study aims to understand the process, reasons for the actions of farmers and analyze the factors that influence farmers to switch commodities. The number of respondents is 46 farmers selected using Simple Random Sampling. Description and multiple regression are used in this research. The results showed that the commodities convertion is done in some stages. The main reason is that farmers are able to earn income from their initial plants while they wait their new crops starting to produce. There are three reasons that farmers switch of social, economic, and agronomists. Social reasons, namely, to see the success of a friend of $41.30 \%$, follow friends $39.13 \%$, and their-owned beliefs $26.08 \%$. Economic reasons is the high price of cocoa $60.86 \%$, continuity of production $100 \%$ and marketing easy in $93.47 \%$. Agronomic reasons, namely cocoa seedlings are easy to get $95.65 \%$, maintenance / cultivation is easy $89.13 \%$, and easy in post- harvest handling $93.47 \%$. The results of regression analysis showed the number of dependents, a price comparison index, previous farm receipts, the coffee plant age, perception of control of the commodity, ease of cultivation and post harvest simultaneously significantly affect the percentage of land area converted. While the partial factors of coffee plant age and the perception of the commodity rather have real impact on the land area converted commodities.
\end{abstract}

Keywords: Commodities Convertion, Converion Process, Influenced Factors

\section{PENDAHULUAN}

Perkebunan kopi saat ini sedang mengalami masa tidak menentu, disebabkan oleh rendahnya harga kopi, diikuti pula oleh penurunan produktivitas kopi petani. Kondisi ini dirasakan petani sangat sulit untuk memenuhi kebutuhan hidup jika masih mengandalkan usahatani kopi. 
Penurunan produktivitas tersebut erat kaitannya dengan perubahan-perubahan lingkungan di daerah tropika sebagai akibat dari pembukaan hutan, pemanasan global sebagai akibat emisi $\mathrm{CO} 2$ dan gas-gas rumah kaca yang berlebihan. Kurangnya pengetahuan di tingkat petani mengenai cara-cara dalam melakukan pengolahan secara baik juga merupakan salah satu yang dapat mempengaruhi kualitas dan kuantitas kopi, karena dalam mengelolah biji kopi dari proses pemetikan sampai ke penjemuran hingga ke penggilingan petani masih menggunakan cara-cara tradisional. Ini juga dapat mempengaruhi keuntungan petani karena kopi dengan kualitas rendah, harganya juga akan rendah.

Menurut Himpunan Kerukunan Tani Indonesia (2010), Syahrul (2009), dan Verbist dkk (2004), beralih petani ke tanaman lain lantaran beberapa hal. Harga kopi sempat anjlok sangat rendah sampai beberapa tahun menyebabkan kekecewaan masyarakat, sehingga secara ekonomis tidak menguntungkan lagi dan tidak dapat dijadikan andalan sebagai sumber mata pencarian keluarga. Menyebabkan petani beralih dari tanaman kopi ke tanaman lain.Selain itu, setelah masuknya tanaman cokelat (kakao) yang pengolahan pasca panennya lebih sederhana, banyak pekebun yang mengganti kopi dengan tanaman tersebut. Pengolahan pasca panen kopi dinilai petani lebih sulit daripada kakao. Lamanya siklus panen pertama dan panen berikutnya pada setiap tahun dan kurangnya proses perawatan terhadap tanaman kopi, baik dari proses pengendalian hama dan pemupukan juga menyebabkan kualitas dan kuantitas produksi kopi juga mengalamai penurunan.

Namun seiring dengan dinamika pembangunan yang ditandai dengan transformasi struktur ekonomi dan demografi, salah satunya terjadi fenomena petani akan mulai beralih untuk menanan tanaman yang lebih menguntungkan dari tanaman sebelumnya seperti usahatani kakao yang dilakukan petani di Desa Tertap Kecamatan Jarai Kabupaten Lahat. Hal ini terjadi karena adanya anggapan petani bahwa usahatani kakao lebih menjanjikan dari segi pendapatan dan kesejahteraan petani. Alasan lain, cara budidaya tanaman kakao lebih mudah dilakukan dari pada tanaman kopi. Data yang tercatat di Dinas Kehutanan dan Perkebunan Kabupaten Lahat Tahun 2010 menunjukkan luas lahan yang telah digunakan untuk perkebunan kakao di Kabupaten Lahat adalah 2.834 hektar dengan tingkat produksi 698,05 ton/tahun dan untuk luas areal perkebunan kakao di Kecamatan Jarai sebesar 860 hektar, dengan jumlah produksi sebesar 300 ton.

Beralihnya komoditi kopi ke kakao disambut baik oleh petani. Peralihan ini cukup berdampak positif, biasanya petani kopi panen satu kali dalam satu tahun, akan tetapi dengan beralihnya ke tanaman kakao petani dapat dua kali panen dalam satu tahun, dan dalam satu bulan dapat beberapa kali panen tergantung dengan masa tanam kakaonya. Menurut Wahyudi, dkk (2008) buah kakao akan masak pada waktu 5,5 bulan (di dataran rendah) atau 6 bulan (di dataran tinggi) setelah penyerbukan. Panen dilakukan 7-14 hari sekali. Selain itu, beralihnya suatu komoditi tanaman merupakan keputusan yang tidak mudah karena usaha perkebunan merupakan investasi jangka panjang dimana pada kasus ini petani sudah melakukan investasi ke sektor 
perkebunan dan kemudian mengganti tanamannya dengan sektor perkebunan lain. Berdasarkan hal ini maka penelitian bertujuan untuk memahami proses, alasan petani dan menganalisa faktor-faktor yang mempengaruhi petani melakukan alih komoditi kopi ke kakao di Desa Tertap Kecamatan Jarai Kabupaten Lahat.

\section{METODE PENELITIAN}

Penelitian ini dilakukan di Desa Tertap Kecamatan Jarai dengan pertimbangan desa ini mengalami alih komoditi tertinggi dan merupakan desa yang pertama kali terjadi alih komoditi kopi ke kakao. Responden dalam penelitian ini adalah 46 orang petani yang ditentukan dengan simple random sampling. Penelitian dilakukan pada Mei 2011. Data yang digunakan dalam penelitian ini adalah data primer dan data sekunder.

Untuk memahami proses terjadinya alih komoditi dilakukan studi kasus terhadap 2 orang petani yang diplih secara purposif dengan alasan mereka dianggap sebagai early adopter di desanya dan untuk memahami alasan petani dalam alih komoditi kopi ke kakao digunakan analisa statistik deskriptif.

Selanjutnya untuk menganalisa faktor-faktor yang mempengaruhi petani dalam alih komoditi dengan menggunakan analisis regresi linear berganda yaitu suatu metode pengujian berganda untuk menggambarkan pengaruh variabel bebas (independent) terhadap variabel tak bebas (dependent). Secara matematis model yang digunakan adalah sebagai berikut:

$$
Y_{t}=\beta_{0}+\beta_{1} X_{1 t}+\beta_{2} X_{2 t}+\beta_{3} X_{3 t}+\beta_{4} X_{4 t}+\beta_{5} D_{1 t}+\beta_{6} D_{2 t}+\beta_{6} D_{3 t}+e_{t}
$$

dimana : $\mathrm{Y}_{\mathrm{t}}$ adalah luas lahan yang dialih-komoditikan, jumlah tanggungan keluarga $\left(\mathrm{X}_{1}\right)$; indeks perbandingan harga $\left(\mathrm{X}_{2}\right)$; penerimaan usahatani kopi $\left(\mathrm{X}_{3}\right)$; umur tanaman kopi $\left(\mathrm{X}_{4}\right)$; persepsi terhadap alih komoditi (D1); cara budidaya (D2); dan kemudahan pasca panen (D3). Model tersebut di estimasi dengan menggunkan piranti lunak shazam dengan pendekatan jumlah kuadrat terkecil atau OLS (Ordinary Least Square).

\section{HASIL DAN PEMBAHASAN}

\section{Karakteristik Responden}

Dari hasil penelitian diketahui bahwa rata-rata umur responden adalah 49,28 persentase terbesar dari umur petani kakao di daerah penelitian berada pada kelompok umur 42,34 - 53,66 yaitu sebesar 45,65\%. Hal ini menunjukkan bahwa petani kakao di Desa Tertap umumnya berada pada usia produktif. Pada usia produktif ini menunjukkan potensi tenaga kerja di Desa 
Tertap baik, sehingga peluang peningkatan pengembangan pembangunan khususnya di bidang pertanian terbuka lebar.

Jumlah persentase tingkat pendidikan terbesar adalah 9-12 tahun yaitu $56,52 \%$. Bila diperhatikan dari tingkat pendidikan formal tersebut, maka dapat dikatakan bahwa petani di daerah penelitian ini masih mempunyai tingkat pendidikan formal yang cukup rendah yaitu tamatan SLTP dan tamatan SMA.

Pengalaman berusahatani akan membantu petani dalam mengelola usahataninya. Semakin tinggi pengalaman usahatani seseorang diharapkan dapat meningkatkan kemampuan seseorang untuk mengelola usahataninya dan meningkatkan manfaat yang diinginkan dari usahatani tersebut. Rata-rata pengalaman berusahatani adalah 22,37 tahun dengan kisaran 17,34 - 29,66 tahun sebanyak 17 orang yaitu sebesar $36,96 \%$. Luas kepemilikan lahan garapan petani rata-rata 0,57 ha dengan kisaran $\leq 0,5$ ha sebanyak 34 orang bila dipersenkan sebesar 73,91\%. Hal ini menunjukkan bahwa sebagian petani responden memiliki lahan garapan yang masih relatif sempit. Sempitnya luas lahan garapan tersebut karena bersumber dari harta warisan yang turun temurun yang harus dibagi-bagi. Lahan garapan yang sempit juga menjadi kendala pembangunan pertanian (Nuhung, 2003).

\section{Proses Terjadinya Alih Komoditi}

Proses alih komoditi kopi ke kakao dijelaskan pada bagan 1. Proses alih komoditi ini dibenarkan oleh Plt. Kepala Dinas Perkebunan dan Kehutanan Ibu Zuairiah Aini bahwa pada tahun 2007 diberikan bantuan bibit kakao untuk 25 kepala keluarga (KK). Menurut Ibu Aini ini proses diversifikasi karena kebanyakan alasan ekonomi, meliputi harga, akses pasar, jumlah produksi dan tanaman kakao mudah di jual secara basah, tapi kenyataannya kakao sudah diusahakan secara monokultur. Bantuan tersebut diberikan kepada masingmasing petani sebanyak 250 batang bibit kakao satu buah gunting besar, pupuk $5 \mathrm{Kg}$ dan uang gali lobang sebesar Rp 65.000. Sedangkan menurut Kepala Desa Tertap Bapak Ismet Sadi (55) "Pada awalnya hanya 25 petani yang mencoba menanam kakao, sekarang sudah hampir $80 \%$ petani berganti ke tanaman kakao".

\section{Studi Kasus Petani Sukses dalam Usahatani Kakao}

Responden kasus dalam penelitian ini adalah petani Desa Tertap yang mengetahui atau orang yang terlibat langsung dalam proses konversi lahan kopi menjadi perkebunan kakao, ditentukan dengan sengaja yaitu petani kakao yang sukses dan petani kakao yang mengikuti teman. Responden kasus pertama adalah Bapak Lukman (52) pendidikan terakhir S1. Memiliki jumlah anggota keluarga sebanyak 4 orang dan merupakan pensiunan penyuluh pertanian Kecamatan Jarai.

Semenjak menanam kakao Bapak Lukman mulai merasakan terjadinya peningkatan kesejahteraan antara lain dapat mencukupi kebutuhan rumah tangga sehari-hari dan dapat menyekolahkan dua orang anaknya ke jenjang 
yang lebih tinggi (kuliah) dibandingkan sebelum menanam kakao. Menurut Bapak Lukman. "udem ganti ngai nanam cuklat nih terase juge, nek makan dide sare lagi". (Artinya setelah menanam kakao terasa lebih baik, untuk kebutuhan sehari-hari tidak sulit lagi). Selain itu jumlah produksi dan kecepatan berproduksi merupakan salah satu alasan Bapak Lukman lebih memilih kakao karena hasilnya dapat diperoleh dalam jangka waktu yang pendek dan terus menerus yaitu mingguan atau bulanan, karena diperlukan untuk memenuhi kebutuhan hidup sehari-hari.

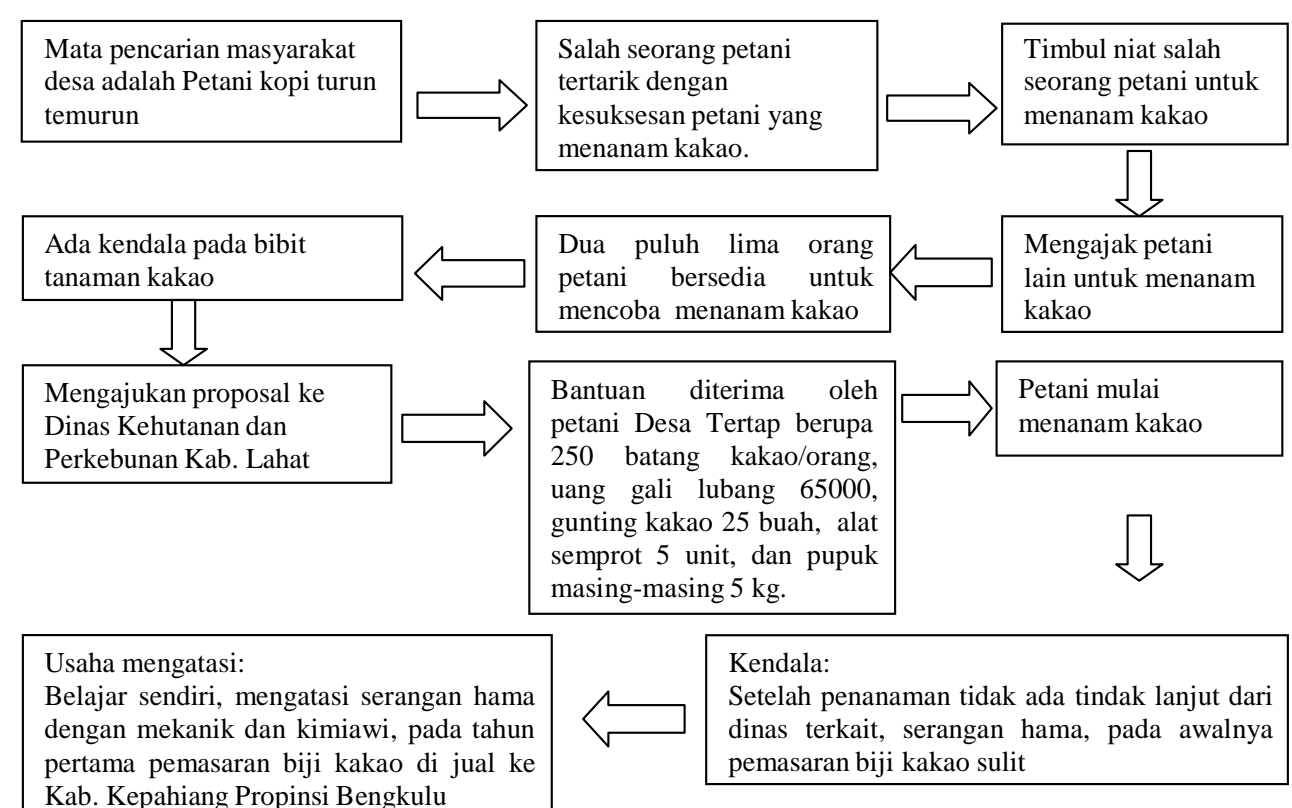

Sumber: data primer diolah (2011)

Awalnya bibit kakao ini di tanam di sela-sela tanaman kopi dengan jarak tanam berkisar antara $10 \times 5 \mathrm{~m}$ dari tanaman kopi, setelah tanaman kakao ini membesar dan mulai berbuah pada umur 1.8 bulan atau lebih dikenal oleh petani pakulagung (panen pertama) maka tanaman kopi disekitar pohon kakao yang telah berbuah di lakukan penebangan (pemangkasan) dan menambahkan tanaman kakaonya sebanyak 350 batang, karena selain tidak menghasilkan buah, tanaman kopi ini juga dapat mengganggu tanaman kakao petani. Selain itu, tanaman kopi sudah termasuk tanaman tua dan petani hanya meneruskan usahatani kopi yang telah ada dan tidak menanam kembali (replanting) kopi robusta tapi masih melakukan perawatan.

Kendala yang muncul pada proses budidaya kakao ini menurut Bapak Lukman adalah tidak ada tindak lanjut dari Dinas Kehutanan dan Perkebunan tentang tanaman kakao bagi para petani, selain itu tanaman kakao mudah terkena serangan hama. Untuk mengatasi serangan hama Bapak 
Lukman menggunakan detan secara kimiawi dan mekanik dengan memangkas daun/dahan dengan gunting kakao serta membungkus buah kakao dengan plastik. Saat ini tanaman kakaonya sudah menghasilkan rata-rata 15 - $20 \mathrm{~kg}$ biji kakao setiap minggunya untuk buah sela.

Untuk pemasaran, pada awalnya Bapak Lukman menjual hasil biji kakao ke Bengkulu dengan menumpang Bus Sarana Sakti, seiring banyaknya lahan kopi yang dialihkan ke kakao maka tempat penjualan biji kakao mulai ramai. Untuk Desa Tertap sudah ada tempat penjualan yang bernama Musi Indah. Bahkan saat panen raya sudah ada tukang ojek (tengkulak) yang bersedia membeli biji kakao basah dari kebun petani dengan harga yang sedikit lebih rendah dari harga biji kakao kering.

\section{Studi Kasus Petani Mengikuti Teman dalam Usahatani Kakao}

Responden untuk studi kasus ke dua adalah Bapak Khodri (65) pendidikan terakhir SD, mulai menanam kakao pada tahun 2009. Memiliki jumlah tanggungan keluarga sebanyak 4 orang. Mulanya Bapak Khodri menanam kakao karena terpengaruh terhadap Bapak Lukman. Seperti penuturan Bapak Khodri. " aku lih nanam cuklat nih nginak Lukman lih pacak beli motor nga nyekolahkah anak". ( Artinya saya menanam kakao kerena melihat Lukman bisa membeli motor dan menyekolahkan anaknya). Bapak Khodri menanam kakao dengan harapan hasil buah tanaman kakao dapat terus berkelanjutan sehingga dapat di panen setiap minggu dan harga kakao yang tinggi.

Penerimaan usahatani kopi sebelumnya dirasa sangat tidak cukup untuk memenuhi kebutuhan keluarga, menurut Bapak Khodri. "ame nak ngandalkah tanaman kawe ni dide cukup nek ngudut". (Artinya kalau cuman mengandalkan usahatani kopi saja tidak cukup, untuk merokok saja susah). Selain itu "kawe ni ngasil taunan, ngguk musim panen banyak pule jeme ngundang bago an, dide datang dek lemak". (Artinya tanaman kopi ini uang yang didapat bersifat tahunan dan akan mudah habis karena pada saat musim panen banyak orang yang mengundang di acara pernikahan, kalau tidak datang tidak menghargai yang mengundang). Selain itu penguasaan lahan yang relatif kecil juga membuat mereka mencari alternatif pekerjaan yang lain selain usahatani kakao.

Bapak Khodri hanya mengusahakan setengah hektar lahannya untuk menanam kakao tidak sepenuhnya langsung beralih menanam kopi, karena tidak punya dana untuk mengusahakan tanaman kakao secara langsung. Tanaman kopi masih dipertahankan sebelum tanaman kakao berbuah, karena masih dapat dimanfaatkan sampai tanaman baru menghasilkan, tetapi apabila tanaman kakao sudah berbuah tanaman kopi akan dipangkas dan diganti dengan tanaman kakao.

Menurut Bapak Khodri, "Taun ni nengkok kawe dide ade bebuah empuk dikit, anye cuklat lah ade bebuah". (Artinya tahun ini kopi saya tidak ada yang berbuah satu batang pun, tetapi tanaman kakao sudah ada yang mulai berbuah). 
Menurutnya tidak berbuahnya tanaman kopin disebabkan karena perubahan cuaca yang tidak menentu.

\section{Alasan-Alasan yang Mempengaruhi Petani Alih Komoditi Kopi ke Kakao}

Dari hasil penelitian dapat diketahui beberapa alasan petani dalam memutuskan untuk beralih menanam kakao. Ada beberapa alasan yang dikemukakan oleh petani yang kemudian dikelompokkan menjadi tiga alasan yaitu agronomis, ekonomi, dan sosial. Alasan petani dalam memutuskan untuk beralih komoditi ke kakao dapat dilihat pada Tabel 1.

Dari Tabel 1, alasan agronomis petani menanam kakao yaitu bibit kakao mudah didapat 95,65\%. Bibit kakao yang di tanam adalah bibit kakao yang didapat dari bantuan dan penyemaian sendiri dengan biji dari hasil seleksi dari petani yang sudah menanam kakao. Pemilihan buah kakao yang akan dijadikan bibit harus masak merata berwarna kuning atau kemerahan kulitnya. Perawatan/budidaya mudah $89,13 \%$. Dalam proses penyiangan untuk tanaman kakao tidak seintensif penyiangan pada tanaman kopi. Menurut Febryano (2009), tanaman kopi diperlukan beberapa kali penyiangan karena tanaman kopi tidak dapat menghasilkan buah bila disekitar pohon kopi ditumbuhi gulma karena tanaman kopi tidak dapat mengalami perebutan unsur hara dengan gulma. Mudah dalam penanganan pasca panen 93,47\%. Kemudahan pascapanen tanaman kakao, selain menguntungkan dari segi ekonomi (penghematan biaya) juga menguntungkan dari segi penggunaan tenaga kerja karena tanaman kakao dalam pemetikan tidak sulit hanya dipetik bauhnya saja yang besar sedangkan kopi harus dipetik satu-satu dan memerlukan waktu yang lama.

Tabel 1. Alasan-Alasan Petani Beralih Menanam Kakao

\begin{tabular}{llcc}
\hline No & \multicolumn{1}{c}{ Alasan Petani } & $\begin{array}{c}\text { \% Petani beralih ke } \\
\text { kakao }\end{array}$ & $\begin{array}{c}\text { Rata rata \% } \\
\text { alasan }\end{array}$ \\
\hline 1 & Alasan Agronomis & 95,65 & 92,75 \\
& Bibit Kakao Mudah Didapat & 89,13 & \\
& Perawatan/Budidaya Mudah & 93,47 & 84,77 \\
& Mudah dalam Penanganan Pasca Panen & & \\
& Alasan Ekonomi & 60,86 & 35,50 \\
& Harga Jual Tinggi & 100,00 & \\
& Kontinuitas Produksi & 93,47 & \\
& Mudah dalam Penjualan & & \\
& Alasan Sosial & 41,30 & \\
& Melihat Keberhasilan teman & 39,13 & \\
& Mengikuti Teman & 26,08 & \\
& Keyakinan Sendiri & &
\end{tabular}

Sumber: data primer diolah (2011)

Alasan ekonomi yaitu harga jual kakao tinggi 60,86\%, kontinuitas produksi 100\%, dan mudah dalam penjualan 93,47\%. Alasan ekonomi 
merupakan salah satu alasan petani beralih menanam kakao dikarenakan harga kakao cendrung lebih mahal, tanaman kakao mudah untuk dipasarkan, waktu, tenaga kerja, biaya yang dibutuhkan untuk mengusahakan tanaman kakao tidak terlalu banyak. Kontinuitas produksinya juga berkelanjutan. Dari alasan ekonomi ini terlihat yang menjadi pertimbangan utama petani sebenarnya adalah pendapatan, kontinuitas produksi, dan kecepatan berproduksi. Hal ini menunjukan bahwa orientasi petani sebenarnya masih untuk memenuhi kebutuhan hidup sehari-hari (orientasi subsisten) walaupun hasil dari tanaman kakao sebagai tanaman utama seluruhnya dijual oleh petani (orientasi komersial).

Alasan sosial yaitu melihat keberhasilan teman sebesar 41,30\%, mengikuti teman 39,13\%, dan niat sendiri 26,08\%. Melakukan alih komoditi merupakan inisiatif dan keputusan seorang individu, tapi itu semua tidak terlepas dari unsur sosial masyarakat yang menyebabkan petani lebih mendapatkan pertimbangan dalam melakukan usahatani, sehingga dalam membudidayakan kakao akan menjadi lebih ringan karena adanya bantuan dari orang lain di lingkungan sosialnya, baik anggota keluarga sendiri, kerabat dan tetangga.

\section{Faktor-Faktor yang Mempengaruhi Petani Alih Komoditi Kopi ke Kakao}

Untuk mengetahui faktor-faktor yang mempengaruhi petani dalam alih komoditi kopi ke kakao digunakan fungsi regresi linear berganda (Tabel 2).

Tabel 2 Estimasi Faktor-Faktor yang Mempengaruhi Alih Komoditi Kopi ke Kakao

\begin{tabular}{lrrr}
\hline \multicolumn{1}{c}{ Variabel Bebas } & Koefisien Regresi & Se(bi) & t hitung \\
\hline Jumlah Tanggungan Keluarga (X1) & $-19,769$ & 1,837 & $-1,076$ \\
Indeks Perbandingan Harga (X2) & $-0,38616$ & 8,824 & $-0,04376$ \\
Penerimaan UT Sebelumnya (X3) & $0,90819 \mathrm{E}-07$ & $0,1220 \mathrm{E}-5$ & 0,07443 \\
Umur Tanaman Kopi (X4) & $-10,789$ & 0,4483 & $-2,407^{* *}$ \\
Persepsi Terhadap Alih Komoditi (D1) & 32,598 & 6,013 & $5,421^{* *}$ \\
Cara Budidaya (D2) & 36,659 & 3,908 & 0,9380 \\
Kemudahan Pascapanen (D3) & 66,297 & 5,350 & 1,239 \\
\hline Intersep & 82,813 & & \\
R2 & 0,7900 & & \\
F hitung & 20,425 & & \\
t tabel & 1,697 & & \\
F tabel & 2,26 & & \\
\hline Sumber : & &
\end{tabular}

Sumber : Data Primer Diolah,2011

Keterangan : ${ }^{* *}$ nyata pada taraf $95 \%$

140 | M. Agus Maryanto, Musriyadi Nabiu, dan Septri Widiono. Faktor-Faktor... 
Dari hasil estimasi didapat koefisien determinasi $\left(\mathrm{R}^{2}=0,7900\right)$. Hal ini menerangkan bahwa persentase luas lahan yang dialihkomoditikan dapat dijelaskan oleh jumlah tanggungan keluarga, indeks harga, penerimaan usahatani sebelumnya, umur tanaman kopi, persepsi terhadap alih komoditi, cara budidaya, dan kemudahan pascapanen sebesar $79 \%$, sedangkan sisanya sebesar $21 \%$ disebabkan oleh faktor lain yang tidak diidentifikasi dalam model ini.

Uji $\mathrm{F}$ menunjukkan bahwa nilai $\mathrm{F}_{\text {hitung }}$ lebih besar dari $\mathrm{F}_{\text {tabel }}$ sehingga dapat disimpulkan secara simultan variabel bebas berpengaruh nyata terhadap variabel terikat. Dari hasil analisis regresi, diketahui nilai koefisien regresi umur tanaman kopi bernilai negatif yaitu $-1,0789$ dengan nilai -t hitung $(-2,407$ ) $\leq$ - $\mathrm{t}$ tabel $(-1,697)$, maka Ho ditolak dan Ha diterima yang berarti umur tanaman kakao berpengaruh nyata terhadap luas lahan yang dialihkomoditikan. Hal ini karena semakin tuanya umur tanaman kopi maka semakin banyak petani yang mengalihkan usahatani kopi ke kakao karena produktivitas lahan kopinya mengalami penurunan. Ini terjadi karena faktor cuaca yang berubah-ubah dan petani tidak memiliki biaya untuk melakukan perawatan terhadap tanaman kopinya.

Dari hasil analisis diketahui nilai koefisien regresi persepsi terhadap alih komoditi bernilai positif yaitu sebesar 32,598 dengan nilai t hitung $(5,421)>$ nilai t tabel (1,697), maka Ho ditolak dan Ha diterima yang berarti secara parsial persepsi berpengaruh nyata terhadap luas lahan yang dialihkomoditikan. Dari hasil pengamatan dilapangan bahwa sebagian besar petani mendukung proses alih komoditi, karena diharapkan dapat membantu dalam mengatasi permasalahan ekonomi, dan petani yakin tanaman kakao dapat memberikan keuntungan yang besar bagi petani apabila dibandingkan dengan tanaman lain. Adapun keuntungan tersebut yaitu dari segi kecepatan berproduksi tanaman kakao lebih cepat dibandingkan tanaman kopi. Selain itu tanaman kakao dapat memberikan keuntungan dari segi harga, harga biji kakao lebih mahal dibandingkan dengan harga biji kopi.

Dari hasil analisis regresi di ketahui bahwa faktor lain seperti : jumlah tanggungan keluarga, indeks perbandingan harga, penerimaan usahatani sebelumnya, persepsi terhadap alih komoditi dan cara budidaya tidak berpengaruh terhadap luas lahan yang dialihkomoditikan.

\section{SIMPULAN DAN SARAN}

\section{Simpulan}

Berdasarkan hasi penelitian dan pembahasan yang telah dilakukan, maka dapat disimpulkan sebagai berikut:

1. Proses alih komoditi ini dilakukan secara bertahap sehingga hasil dari tanaman lama masih dapat digunakan sampai tanaman baru menghasilkan. 
2. Pertimbangan utama petani adalah alasan agronomis dan ekonomi. Hal ini menunjukan bahwa orientasi petani sebenarnya masih untuk memenuhi kebutuhan hidup sehari-hari.

3. Jumlah tanggungan keluarga, indeks perbandingan harga, penerimaan usahatani sebelumnya, umur tanaman kopi, persepsi terhadap alih komoditi, cara budidaya dan kemudahan pascapanen secara serempak berpengaruh nyata terhadap persentase luas lahan yang dialihkomoditikan. Sedangkan secara parsial jumlah tanggungan keluarga, indeks harga, penerimaan usahatani sebelumnya, kemudahan pascapanen, dan cara budidaya tidak berpengaruh nyata terhadap luas lahan yang dialihkomoditikan sedangkan faktor umur tanaman kopi, dan persepsi terhadap alih komoditi berpengaruh nyata terhadap luas lahan yang dialih komoditikan.

\section{Saran}

1. Faktor yang berpengaruh nyata dengan alih komoditi sebaiknya dijadikan bahan pertimbangan bagi petani dalam melakukan proses alih komoditi sehingga petani dapat mengambil sikap yang bijak.

2. Perlu kajian yang mendalam mengenai alih komoditi kopi ke kakao dimasa yang akan datang, sehingga akan menyadarkan berbagai kalangan masyarakat setempat mengenai kesejahteraan yang akan diterima oleh petani dari berbagai aspek.

3. Dari ketiga alasan petani beralih, persentase yang paling besar adalah alasan agronomis. Jadi disarankan kepada pemerintah apabila ingin merealisasikan menanam komoditi baru di suatu daerah hendaknya pemerintah perlu meningkatkan penyuluhan-penyuluhan tentang komoditi tersebut secara berkelanjutan sehingga ketika petani beralih ke komoditi tersebut petani sudah mengetahui apa keunggulan dan kelemahan dari komoditi itu.

\section{DAFTAR PUSTAKA}

Febryano, I. G. et al. 2009. Pengambilan Keputusan Pemilihan Jenis Tanaman dan Pola Tanam di Lahan Hutan Negara dan Lahan Milik : Studi kasus di Desa Sungai Langka, Kecamatan Gedong Tataan, Kabupaten Pesawaran Propinsi Lampung. Jurnal Forum Pascasarjana 32 (2) 129-141, 2009.

[Himpunan Kerukunan Tani Indonesia] Propinsi Lampung. 2010. Petani Tinggalkan Budidaya Kopi. http://www.hkti-lampung.com/news/ 138petani-tinggalkan-budidaya-kopi.html.(Diakses 12 September 2011)

Nuhung, I. A. 2003. Membangun Pertanian Masa Depan, Suatu Gagasan Pembaharuan. Aneka Ilmu, Semarang.

Syahrul, S Azul. 2009. Perbedaan Karakteristik Sosial-Ekonomi, Sumber Informasi Dan Pendapatan Petani Kopi Arabika Dengan Petani Kopi Robusta (Studi Kasus : Kelurahan Sidiangkat Dan Kelurahan Bintang Hulu, Kecamatan 
Sidikalang, Kabupaten Dairi). Skripsi. Departemen Sosial Ekonomi Pertanian. Fakultas Pertanian. Universitas Sumatera Utara. Medan.

Verbist, Bruno., E.P, Andree dan Budidarsono, Suseno. 2004. Penyebab Alih Guna Lahan dan Akibatnya Terhadap Fungsi Daerah Aliran Sungai (DAS) pada Lansekap Agroforestri Berbasis Kopi di Sumatera. Jurnal AGRIVITA 26 (1) 29-38, 2004.

Wahyudi, T. dkk. 2008. Panduan Lengkap Kakao. Penebar Swadaya. Jakarta.

Lampiran 1. Luas Areal Perkebunan Kakao Rakyat di Kabupaten Lahat Tahun 2009-2010

\begin{tabular}{|c|c|c|c|c|c|}
\hline \multirow{2}{*}{ No } & \multirow{2}{*}{ Kecamatan } & \multicolumn{2}{|c|}{ Luas Areal Perkebunan (Ha) } & \multicolumn{2}{|c|}{ Produksi (ton) } \\
\hline & & 2009 & 2010 & 2009 & 2010 \\
\hline 1 & Merapi Barat & 1,63 & 2,00 & 0,00 & 0,00 \\
\hline 2 & Merapi Selatan & 0,00 & 0,00 & 0,00 & 0,00 \\
\hline 3 & Merapi Timur & 7,50 & 240,00 & 1,35 & 140,00 \\
\hline 4 & Lahat & 5,00 & 5,00 & 1,90 & 4,00 \\
\hline 5 & Pulau Pinang & 0,00 & 0,00 & 0,00 & 0,00 \\
\hline 6 & Gumay Ulu & 0,00 & 50,00 & 0,00 & 0,00 \\
\hline 7 & Pagar Gunung & 0,00 & 61,00 & 0,00 & 0,00 \\
\hline 8 & Kota Agung & 127,00 & 177,00 & 14,31 & 7,00 \\
\hline 9 & Tanjung Tebat & 72,00 & 99,00 & 3,05 & 7,00 \\
\hline 10 & Mulak Ulu & 109,00 & 112,00 & 11,60 & 23,00 \\
\hline 11 & Jarai & 400,00 & 860,00 & 124,10 & 300,00 \\
\hline 12 & Muara Payang & 568,00 & 570,00 & 98,52 & 116,00 \\
\hline 13 & Pajar Bulan & 425,00 & 525,00 & 52,50 & 75,00 \\
\hline 14 & $\begin{array}{l}\text { Tanjung Sakti } \\
\text { PUMI/PUMU }\end{array}$ & 6,00 & 53,00 & 0,70 & 8,00 \\
\hline 15 & Gumay Talang & 13,70 & 13,00 & 0,00 & 0,00 \\
\hline 16 & Pseksu & 17,50 & 22,00 & 5,04 & 14,00 \\
\hline 17 & Kikim Timur & 2,00 & 23,00 & 0,62 & 1,00 \\
\hline 18 & Kikim Selatan & 2,00 & 11,00 & 0,62 & 1,00 \\
\hline 19 & Kikim Tengah & 0,00 & 2,00 & 0,00 & 0,00 \\
\hline 20 & Kikim Barat & 0,00 & 9,00 & 0,00 & 0,00 \\
\hline \multicolumn{2}{|c|}{ Jumlah } & 1756,33 & 2834,00 & 314,31 & 696,00 \\
\hline
\end{tabular}

Sumber: Dinas Kehutanan dan Perkebunan, 2010 
ISSN: 1412-8837

Lampiran 2. Luas Areal Perkebunan Kakao Rakyat di Kecamatan Jarai, 2010

\begin{tabular}{llrr}
\hline No & \multicolumn{1}{c}{ Desa } & Luas Areal Perkebunan $(\mathrm{Ha})$ & Jumlah Petani $(\mathrm{KK})$ \\
\hline 1 & Sadan & 150,00 & 137,00 \\
2 & Penantian & 90,00 & 30,00 \\
3 & Bandar Aji & 40,00 & 25,00 \\
4 & Tertap & 200,00 & 256,00 \\
5 & Kedaton & 15,00 & 26,00 \\
6 & Muara Tawi & 2,00 & 3,00 \\
7 & Jemaring & 5,00 & 12,00 \\
8 & Pelajaran & 15,00 & 26,00 \\
9 & Pamah Salak & 70,00 & 40,00 \\
10 & Nanti Giri & 3,00 & 8,00 \\
11 & Aromantai & 65,00 & 40,00 \\
12 & Jarai & 40,00 & 50,00 \\
13 & Tanjung Menang & 0,00 & 0,00 \\
14 & Serambi & 25,00 & 18,00 \\
15 & Suka Nanti & 0,00 & 0,00 \\
16 & Mangun Sari & 25,00 & 20,00 \\
17 & Lubuk Saung & 65,00 & 50,00 \\
18 & Karang Tanding & 0,00 & 0,00 \\
19 & Pagar Dewa & 50,00 & 40,00 \\
20 & Gunung Megang & 0,00 & 0,00 \\
21 & Gunung Kaya & 0,00 & 0,00 \\
\hline
\end{tabular}

144 I M. Agus Maryanto, Musriyadi Nabiu, dan Septri Widiono. Faktor-Faktor... 